Luís Antonio Bitante Fernandes

Universidade Federal de Mato Grosso, Cuiabá, MT, Brasil

Águeda Aparecida da Cruz Borges

Universidade Federal de Mato Grosso, Cuiabá, MT, Brasil

Rodolfo Pinheiro Bernardo Lôbo

Universidade Federal de Mato Grosso, Cuiabá, MT, Brasil

\title{
Travestilidade às avessas - a desconstrução de uma "paródia" identitária
}

Resumo: Neste artigo, fazemos uma discussão acerca das chamadas identidades de gênero, dada a complexidade e a emergência à questão, principalmente, nos últimos tempos. O propósito é explorar ambiguidades discursivas apresentadas no processo em que se identifica uma travesti, residente na cidade de Barra do Garças/MT que, no discurso de percepção de si, deixa marcas de estranhamento do próprio corpo. Sob o nosso parecer, tais marcas levam a uma desconstrução de suas identidades, num movimento performático e contraditório no qual se traveste de homem, mesmo se encontrando em um corpo masculino, não o reconhecendo. Ao fazer uso de seu órgão sexual de nascimento, o faz na elaboração de estratégias de sobrevivência. A fundamentação das análises são as teorias de gênero e queer, propostas de desconstrução dos significados da sexualidade.

Palavras-Chave: Desconstrução; Gênero; Sexualidade; Travestilidade; Identidade.

\section{(c) (i)}

Esta obra está sob licença Creative Commons.

1 "Garota de Ipanema" (1962), composta por Vinicius de Moraes e Antônio Carlos Jobim, da qual a versão definitiva foi refeita por Vinicius, inspirado em Helô Pinheiro (hoje Garota de Ipanema), que passava frequentemente em frente ao Bar Veloso.

\section{Introdução}

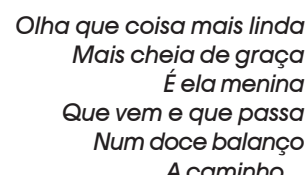

A epígrafe' é uma estrofe de uma famosa composição poética/musical escrita em homenagem a um modelo de beleza feminina cuja inspiração é ejetada das curvas do 


\footnotetext{
${ }^{2}$ A pesquisa foi desenvolvida no município de Barra do Garças MT (15 $\left.53^{\prime} 24^{\prime \prime} \mathrm{S}, 52^{\circ} 15^{\prime} 24^{\prime \prime} \mathrm{W}\right)$ cidade localizada na bacia do rio Araguaia, que divide os estados de Mato Grosso e Goiás. A cidade é cortada pela rodovia BR-158, o que faz dela, como outras, se uma cidade que recebe um fluxo grande de transeuntes devido ao escoamento de grãos para outros estados.
}

corpo de uma bela jovem que caminhava, rumo à praia, pela calçada em frente ao bar frequentado pelos compositores. Esse poema/canção faz menção a um imaginário de beleza feminina idealizada pelo olhar masculino; imaginário imposto por padrões sociais, históricos, ideológicos e culturalmente construído sob a égide heteronormativa.

Esses mesmos versos poderiam servir à inspiração do olhar de si, no/pelo espelho que reflete a beleza que a travesti percebe na construção, afirmação e reconhecimento de um corpo marcado pela identidade de gênero que subverte a ordem, como exposto no primeiro parágrafo. Como travesti entende-se a pessoa que se assume e/ou se identifica com características físicas, sociais e culturais de gênero diferentes do "sexo" que the é atribuído no nascimento e isso não significa negação do sexo genital (Jaqueline Gomes de JESUS, 2012).

Como já anunciado no resumo, o propósito deste trabalho é explorar as ambiguidades discursivas do processo no qual uma travesti, residente na cidade de Barra do Garças - MT, ${ }^{2}$ se identifica como pessoa humana e demonstra, na percepção de si, o estranhamento do seu corpo. Ao estranharse, na própria afirmação, imprime uma posição-sujeito de um gênero compulsório. Essa discursividade transitará entre a negação do corpo masculino e o uso do 'corpo negado' como forma de autoproteção, transgredindo as normas vigentes na sociedade em relação ao comportamento esperado e constituído historicamente. Desse modo, produz uma performatividade fora das fronteiras da heteronormatividade.

Um dos caminhos que nos possibilitou pensar no processo de desconstrução discursiva do gênero compulsório do sujeito da pesquisa foi percebê-lo discursiva, cultural e historicamente na condição atribuída e associada ao sexo de nascimento, ou seja, uma pessoa que se vê em um 'corpo estranho', dotado de um sexo que lhe atribui um gênero na contradição com o não reconhecimento desse mesmo gênero. Percebemos, nesse jogo, que a travestilidade não é a apropriação de outro gênero, mas, como afirma Judith BUTLER (2003), é uma paródia da ideia, mesmo, de gênero, e que só terá a existência pela repetição estilizada de atos.

Observamos, no desenvolvimento da pesquisa, que a discursividade, na construção de si, está permeada de aceitação e incorporação de "papéis sociais" impostos a um ser dotado de um corpo masculino, como forma de estratégia de sobrevivência, mas, ao mesmo tempo, produzindo um estranhamento, uma vez que lhe causa uma recusa do gênero compulsoriamente atribuído por sua genitália.

A problemática envolveu o debate sobre identidades de gênero, em que buscamos, na materialidade discursiva da escuta de História de Vida, as marcas para a produção 
3 Projeto: "Identidades possíveis: uma análise na perspectiva de gênero e sexualidade"; cadastrado na UFMT.
${ }^{4}$ Pessoa que nasceu com genitália masculina e foi lhe atribuída, compulsoriamente, uma identidade de gênero de acordo com seu "sexo". ${ }^{5}$ Identidade de Gênero à qual a colaboradora se reconhece. das análises. Essa pesquisa, que parte da compreensão de identidades possíveis, ${ }^{3}$ manifestas em reproduções das próprias identidades nas práticas sociais, presentes em representações de gêneros, tomou como referencial cultural a masculinidade hegemônica/dominante (Robert W. CONNELL; MESSERSCHMIDT, James W. (2013) como modelo que sustentará o processo de desconstrução na análise, no aprofundamento de conceitos para o debate teórico-metodológico.

Visamos à compreensão da formação e afirmação de identidades, construídas socialmente, por meio de valores tradicionais do ser homem, pautados na percepção da heteronormatividade compulsória e da contribuição do entendimento da diferença associada à ideia do reconhecimento como forma de transformação social. Esse processo possibilita a transformação das relações de poder, do lugar que o Outro ocupa (Richard MISKOLCl, 2013) na ruptura de paradigma. A seleção de recortes da história de vida da colaboradora que materializa parte de sua existência, na elaboração deste artigo, é devido à riqueza de detalhes que sensibilizaram nosso imaginário de pesquisadores(a), de certa forma, distantes da condição do Outro. Esse distanciamento, também, se dá pela própria história de vida de ambos, colaboradora e pesquisador(a), que são pautadas por normas baseadas na determinação heterossexual. Assim, a desconstrução se fará presente na base desse imaginário, pois entendemos que essa é uma forma de as aproximações se tornarem possíveis e de se estabelecer uma relação de confiança mútua.

A partir de entrevista aberta, desenvolveu-se uma linha de diálogo que nos trouxe a percepção de vida e de história da entrevistada. O tratamento atribuído ao "corpus" se fundamenta em princípios éticos, ora pelas iniciais do nome de nascimento - M.A. ${ }^{4}$, ora pelas iniciais do nome social $-M .{ }^{5} \mathrm{O}$ uso de M.A. será empregado quando ela se apresentar como homem e, como tal, descrever suas estratégias de sobrevivência; e $M$. será empregado quando ela, discursivamente, mostrar marcas de identificação do reconhecimento como mulher e, consequentemente, da percepção feminina de si.

Reiteramos que M. e M.A. "é a mesma" pessoa, o fato é que $M$. se traveste em M.A.. Pode parecer estranho ao leitor, mas o que procuramos ressaltar é que a lógica do se travestir também se mostra desconstruída e, portanto, num ato de inversão performativa, uma vez que M.A. é possuidor de um gênero compulsório masculino e que $M$. é a forma pela qual ela se reconhece.

Na construção discursiva de suas histórias e percepções de mundo, deflagramos uma contradição entre o estar M.A. e o ser M.. No primeiro caso, há uma inversão, como veremos, da travestilidade, isto é, mesmo tendo nascido num

Estudos Feministas, Florianópolis, 25(2): 473-494, maio-agosto/2017 475 
corpo masculino e recebido compulsoriamente a identidade de gênero masculina, ela subverte essa ordem heteronormativa, quando não é $M . A$. que se traveste em $M$., mas, o contrário; é $M$. que se traveste em M.A..

Essa estratégia de estar M.A., portanto, de se travestir em homem, é, sob o nosso parecer, uma forma de sustentação para a sobrevivência, pois é no espaço das relações de trabalho que ela está M.A.. Contudo, estar M.A. não lhe tira o ser $M$.. Os trajes masculinos que, pelo imaginário, the conferem uma posição de respeito, por exemplo, não impedem que ela continue se percebendo e se reconhecendo como M.. Por isso, a complexidade dessa relação consigo mesma, na inversão de si, produz o que compreendemos como uma condição subversiva da normatividade.

Todas as entrevistas foram realizadas com M.A., assim, vale lembrar que $M . A$. se assumirá, em vários momentos de sua fala, como $M$., que, enquanto mulher trans, revela um embaraço de categorias ao desestabilizar as incongruências das identidades de gênero e de sexo. Entendemos que, nos momentos em que M.A. se diz mulher trans, é no sentido de reivindicar o reconhecimento de si como tal, em termos sociais.

As histórias presentes nas narrativas da colaboradora se passam na cidade de Barra do Garças e região. A cidade tem como particularidade seu crescimento devido a uma das vias principais, a BR 158, que corta a cidade, sendo uma passagem de grande tráfego de veículos pesados que transportam parte da produção de grãos da região rumo às indústrias e aos portos de exportação do sul e sudeste. Além do mais, é uma cidade com diversos atrativos relacionados à natureza, como o Rio Garças, o Rio Araguaia e o Parque da Serra Azul, os quais atraem turistas de todas as partes do Brasil.

Com o fluxo intenso de caminhões e carretas, postos de combustíveis se instalam nas margens da rodovia BR 158 e nas proximidades do perímetro urbano. Esses espaços se tornam, em geral, pontos de prostituição. Já próximos à parte central da cidade há pontos de prostituição ocupados, mais especificamente por travestis, espaços que, tendo o período diurno destinado ao comércio, portanto, não residenciais, servem como local de prostituição de travestis no período em que as portas se fecham e as luzes se apagam.

Assim, esses espaços de prostituição se subdividem dentro da lógica construída pelas pessoas que ocupam e usufruem da cidade. A parte mais periférica da cidade, onde se localizam os postos de combustíveis, destinados, principalmente, aos caminhoneiros, produz estratégias de prostituição nas quais aquelas, aqueles e aquelxs que oferecem este tipo de serviço se misturam. A prostituição, no perímetro mais central da cidade, é destinada a um público local, onde, em observações realizadas, percebemos que a espacia- 
lização é fruto de uma negociação velada, entre a cidade e as travestis. O permitido não se mostra presente, mas, na opacidade, funciona nas movimentações naquele espaço. Criam-se formas simbólicas de uso do espaço, onde se esquivar em sombras de árvores e postes possibilita o exercício da atividade e, ao mesmo tempo em que dá a sensação de segurança, produz o efeito de sentido não incômodo, do não importuno para a sociedade local.

Os referenciais teóricos que darão suporte para compreender a existência desse sujeito enquanto um ser social envolvido nas tramas e relações estabelecidas em seus espaços de vivência seguem adiante. Dessa forma, categorias como Gênero, Corpo, Sexualidade, Identidade e Travestilidade se entrelaçarão num diálogo teórico com os procedimentos metodológicos desconstrutivistas, aproximando-se da Teoria Queer.

\section{Um diálogo teórico: a (des)construção dos gêneros}

A (des)construção, propositalmente, aqui, apresentada com o prefixo 'des' entre parênteses, não significa apenas o que a gramática normativa indica como negação, pois pensamos a desconstrução, enquanto proposta metodológica de análise, como algo em desenvolvimento. Para tal desenvolvimento, é necessário pensar em um modelo esquemático de superação ou de desfazer modelos teóricos que impliquem minar, perturbar e subverter os termos que afirma e sobre os quais o próprio discurso se afirma. Sendo assim, são revistos ou desconstruídos no sentido de propor uma problematização do gênero passando por uma desconstrução do mesmo e pelo aprofundamento das relações acerca dos gêneros na contemporaneidade (Lúcia Osana ZOLIN, 2005).

A proposta queer está pautada na luta em prol da homossexualidade, em sua forma de atuar acadêmica e politicamente. Ao pensarmos o regime de verdade, queer visa superar o binômio hetero-homo e propõe a relação normaanormal. Essa superação reverte a luta política, proposta que, anteriormente, estava baseada na defesa da homossexualidade e agora se posiciona na crítica aos regimes de normalização. Deste modo, numa perspectiva da diferença, percebemos que a concepção de poder não é repressora, mas, sim, de disciplina/controle.

Com a proposta queer, percebemos que há o surgimento de uma nova política de gênero. Para Butler (2003), essa nova política surge da materialização das demandas dos novos sujeitos e isso leva a revisitar gênero, corpo, sexualidade, identidade e travestilidade em suas interligações. Ao revisitar essas categorias, encontramos contribuições significativas no 
processo da desconstrução das oposições binárias (Jacques DERRIDA, 2011), como homem e mulher, presença e ausência, isto é, trata-se de se apoiar na convicção de que oposições como essas não são absolutamente naturais, nem inevitáveis, mas construções que podem ser desconstruídas.

O Gênero, enquanto papel diretamente relacionado à vida social, indica um conjunto de expectativas sobre os comportamentos sociais de pessoas por estarem estreitamente relacionadas a um determinado sexo e não a outro. Desta forma, prescrever, discursivamente, o que é ou não "natural" nos comportamentos de cada sujeito é parte de um conjunto de estratégias que vão se fixando nas estruturas sociais e que vão reproduzindo estereótipos profundamente arraigados.

Para Joan W. SCOTT (1990), a utilização do "gênero (gender) como um elemento constitutivo das relações sociais fundadas sobre as diferenças percebidas entre os sexos é um primeiro modo de dar significado às relações de poder" (p. 14). Assim, podemos definir gênero como:

[...] ○ gênero de um ser humano é o significado social e político historicamente atribuído ao seu sexo. Nascemos macho ou fêmea. Somos feitos como um homem ou uma mulher. E o processo de fazer homens e mulheres é então histórica e culturalmente variável; consequentemente, o ser é potencialmente modificado através da luta política e das políticas públicas (Sônia ALVAREZ, 1997, p. 15).

e, ainda,

[...] processo através do qual indivíduos que nasceram em categorias biológicas de macho ou fêmea, tornamse categorias sociais de mulheres e homens pela aquisição de atributos de masculinidade e feminilidade, definidos localmente (INSTRAW, 1995, p. 15).

Nas mesmas relações de poder que irão se estabelecer histórica e culturalmente em que o Gênero aparece como um mecanismo dessa estrutura de poder, podemos ver que a "ideia que o sexo é um efeito e não causa e, mais que isso, um efeito repetido" (Sara SALIH, 2013, p. 113). Para Butler (2003), nesse sentido, gênero é a "estilização repetida do corpo, um conjunto de atos repetidos no interior de um quadro regulatório altamente rígido que se cristaliza ao longo do tempo" (p. 33), o que acarreta a produção de uma aparência para produzir uma "aparência de substância, de uma espécie de ser natural" (BUTLER, 2003, p. 33).

A categoria Gênero, enquanto categoria historicamente instituída no cenário das lutas políticas de mulheres, surge na chamada segunda onda do Feminismo para combater as posições daqueles que justificam as desigualdades 
sociais entre homens e mulheres, remetendo-se, geralmente, às características biológicas.

É imperativo, então, contrapor-se a esse tipo de argumentação. É necessário demonstrar que não são propriamente as características sexuais, mas é a forma como essas características são representadas ou valorizadas, aquilo que se diz ou se pensa sobre elas que vai constituir, efetivamente, o que é feminino ou masculino em uma dada sociedade e em um dado momento histórico (Guacira Lopes LOURO, 2001a, p. 21).

Visando, portanto, rejeitar o determinismo biológico, implícito em discursos nos quais são utilizados termos como sexo ou diferença sexual, gênero aparece como o caráter fundamentalmente social das distinções baseadas no sexo (SCOTT, 1990). Desta forma, para Scott (1990), o gênero serve como uma ferramenta analítica e, ao mesmo tempo, uma ferramenta política.

Como categoria que permite uma abordagem política, ela se faz de apelo fortemente relacional, assim, se refere a mulheres, homens, transexuais, homossexuais, enfim, a todas(os) que se relacionam tomando como base a sexualidade e identidade de gênero. Observa-se que, para o fato das caracterizações de social e relacional, para Louro (2003), não se devem levar a conferir a categoria gênero à construção de papéis masculino e feminino.

O fato de remetermos o caráter social para o gênero não nega que esse se constitui com ou sobre corpos sexuados e, que, portanto, a prática social se dirige aos corpos. Numa perspectiva estruturalista, implica a compreensão da alteridade, ou seja, a existência do masculino está associada ao seu oposto, o feminino. Desse modo, o gênero se constrói sobre o corpo biológico, que é sexuado. Temos, então, a possibilidade de vários masculinos e femininos.

Para os pós-modernos, gênero pode ser mutável. Temos, assim, a presença de múltiplos gêneros e não somente o masculino e o feminino. Macho e fêmea como uma contingência que pode ser mudada graças às novas tecnologias. O conceito passa a exigir que se pense de modo plural, dentro da fluidez que as relações permitem, acentuando que os projetos e as representações sobre mulheres, homens e outros são diversas.

Butler (2003), em Problemas de Gênero, desenvolve o argumento de que o gênero, como referendado anteriormente, é a estilização repetida do corpo, um conjunto de atos repetidos no interior de um quadro regulatório altamente rígido que se cristaliza ao longo do tempo para produzir a aparência de substância, de uma espécie de ser natural.

Para os pós-estruturalistas, gênero se constitui pela linguagem, isto é, o gênero se apresenta, no discurso, como 
linguagem que orienta nossas ações, portanto, nessa perspectiva, somos sujeitos permeados por discursos. Essa construção discursiva nos aproxima da teoria Queer ao problematizar o sujeito marcado pelas ciências humanas e sociais, por uma hegemonia da perspectiva masculina sobre a psique enquanto tendência à heterossexualidade do sujeito.

Corpo, teoricamente pensado, é uma invenção do século XX. A psicanálise, com os estudos de Freud, decifrou a histeria de conversão procurando compreender os enunciados de muitas interrogações que surgiram e em que o inconsciente fala através do corpo. Segundo Jean-Jacques COURTINE (2011), esse passo foi decisivo, pois abriu questionamentos sobre somatizações, levando-se em conta a imagem do corpo na formação do sujeito.

O segundo passo na teorização do corpo foi elaborado pela fenomenologia, com Husserl. Ele designava o corpo humano como o "berço original", o que possibilitou ao existencialismo formular a concepção de que o corpo é visto como uma "encarnação da consciência" em seu desdobramento no tempo e no espaço.

A terceira etapa vem com a antropologia, em que Marcel Mauss, ao pensar a "técnica corporal", propõe explicar a ligação do corpo ao inconsciente, isto é, o corpo preso ao sujeito e inserido nas formas sociais da cultura. Nessa onda, o fim da década de 1960 é marcado por movimentos individualistas e igualitários, de protestos contra o peso das hierarquias culturais, políticas e sociais, em que vemos o corpo desempenhar um papel fundamental para romper com os discursos e as estruturas do poder. O corpo parecia estar do lado das categorias oprimidas e marginalizadas: as minorias de raça, classe ou de gênero (COURTINE, 2011).

Percebemos que, estando o corpo ao lado das categorias oprimidas, ele será

investido no contexto das lutas travadas pelos direitos das minorias no decorrer dos anos 1970: um lugar importante da repressão, um instrumento crucial da liberdade, a promessa de uma revolução" (COURTINE, 2011 , p. 9).

Assim, podemos assumir o Corpo como algo que seja interpelado por sexo e que este será uma construção discursiva. Em Butler (2003), observamos que, ao rejeitar a distinção entre sexo e gênero, a autora afirma que sexo é gênero. Portanto, o corpo não pode existir fora do discurso genereficado, isto é, algo que irá se materializar através do discurso.

Por ser assim, o gênero irá se diferir não apenas entre as sociedades ou a dados momentos históricos, mas estará demarcado no interior das sociedades ao considerar os 
${ }^{6}$ Trecho da súmula do Simpósio Temático 87, intitulado "Mulheres em discurso: processos de subjetivação e práticas de resistência", coordenado por Águeda Aparecida da Cruz Borges (Universidade Federal de Mato Grosso), Mónica Graciela Zoppi-Fontana (Universidade Estadual de Campinas) no Fazendo Gênero 10. Florianópolis, 2013. diversos grupos que as compõem, como étnicos, religiosos, raciais, de classe e outros, no discurso. Vejamos o que diz Mónica Graciela ZOPPI-FONTANA (2013) na súmula proposta pelo GT 87:6

Os dispositivos de enunciação permitem, historicamente, a produção da subjetividade, na contradição de filiações de sentidos e memórias discursivas a partir das quais se constroem as identificações, tanto de gênero, quanto outras também entrelaçadas ao longo da história, como as de posicionamento ideológico, filiações étnicas, inscrições sociais e territorialidades rurais e urbanas, representações políticas, mediação midiática.

Se o corpo é algo como dito natural e se o gênero não é dessa mesma ordem natural, como defini-los? Há a existência de uma identidade de gênero ou é possível (re)defini-la? A resposta pode ser dada em dois momentos: um primeiro pela dimensão do invisível - a subjetividade; e o segundo apresentado na sua forma visível - a forma de se apresentar ao mundo como membro de um determinado gênero. Essas duas formas entram em contradição e se confronta a elaboração da existência das travestis. Corpo e mente em uma constante reelaboração de percepções da sexualidade.

Assim, a percepção da sexualidade, vista pelo senso comum, atribui elementos relacionados aos atos sexuais, o que diminui a possibilidade enquanto formas de percepção de nossa própria condição. Em termos mais abrangentes, a sexualidade pode ser vista como o modo como as pessoas se relacionam, desejam, expressam afetos, amam e organizam suas vidas (MISKOLCI, 2014).

Compreendida desta forma, ainda, segundo Miskolci (2014), a sexualidade "se revela uma questão que vai muito além de decisões privadas, pois ela é criada e moldada pelo convívio no espaço público em processos de socialização diversos" (p. 14).

Usada a partir do século XIX para denominar o campo de força de nossos desejos, a motivação para a busca do prazer - físico, psíquico, social e intelectual - em todas as fases de nossas vidas, o que envolve o sexo, o amor, o erotismo e a procriação. A sexualidade não é compreendida como resposta a um instinto, mas como uma característica humana.

Sexualidade e gênero unem-se à identidade e são conceitos que se caracterizam por serem relacionais e terem a propriedade de estabelecerem conexões e separações entre indivíduos e grupos. As identidades serão construídas na relação entre o ponto de vista do sujeito e o ponto de vista do observador.

Os conceitos que estamos adotando reportam ao jogo que se estabelece na apresentação de si e às 
determinações classificatórias realizadas pelos outros. Dessa maneira,

perceber a identidade de gênero dotada de existência concreta ou fixa vai de encontro ao olhar antropológico que postula o caráter dinâmico da vida social e de seu impacto sobre os sujeitos. Ela se apresenta antes como um percurso, em vez de um ponto de chegada. O senso comum considera que uma pessoa, ao ser classificada como homem ou mulher (sexo biológico), terá naturalmente o sentimento e o comportamento esperados de cada uma dessas possibilidades (identidade/papel de gênero masculino ou feminino), e que seu desejo sexual será dirigido para pessoas do sexo e/ou gênero diferente do seu (orientação heterossexual) (Elizabeth ZAMBRANO; Maria Luiza HEILBORN, 2013, p. 416).

O que Zambrano e Heilborn (2013) nos mostram é que os elementos sexo, gênero e orientação são pensados em nossa cultura como um padrão hegemônico de ser homem masculino ou mulher feminina heterossexual. Isso impede de se verificar inúmeras outras combinações entre esses três elementos. A homossexualidade ou homoerotismo são classificações utilizadas, segundo Michel FOUCAULT (1999), em um processo de patologização de outras formas que não condizem com a norma estabelecida. Essas referências marcam pessoas que têm relações sexuais com pessoas do mesmo sexo, se diferindo da orientação sexual socialmente esperada e considerada adequada para um dito sexo.

Há, ainda, outras formas de se expressar em práticas homossexuais podendo ou não corresponder a uma mudança de gênero. Homens que fazem sexo com homens poderão adotar performances socialmente atribuídas à condição masculina, enquanto outros poderão assumir performances consideradas atribuições potencialmente femininas, ainda

${ }^{7}$ Construção de uma imagem com o uso de todos os recursos estéticos e de vestimenta femininos (ZAMBRANO; HEILBORN, 2013).

${ }^{8}$ Optamos por fazer o uso da terminologia "cirurgia de afirmação de gênero" com base no posicionamento político das(os) ativistas trans. que sem travestismo ${ }^{7}$ ou adotando o travestismo em momentos considerados adequados e permitidos.

O que observamos é que, na combinação mostrada por Zambrano e Heilborn (2013), podemos verificar, por um lado, o desenvolvimento de identidades específicas em relação à orientação sexual, tais como: gays, bofes e bichas, que não reivindicam uma identidade de gênero feminina. Por outro lado, o uso de roupas e modificações corporais para se sentirem como mulher, sem fazer o uso da cirurgia de afirmação de gênero ${ }^{8}$ - são os denominados de travestis.

Estas, mantendo total ou parcialmente o corpo biológico de homem - podem, eventualmente, modificá-lo, utilizando hormônios femininos e/ou implantes de silicone -, reivindicam a manutenção dessa ambiguidade corporal e se consideram, 
simultaneamente, homens e mulheres (ZAMBRANO; HEILBORN, 2013, p. 416).

Portanto, do ponto de vista antropológico, temos que qualquer grupo humano estabelece e mantém relações entre si, numa intensidade maior ou menor. Assim, são em relações estabelecidas que as culturas construirão ou se utilizarão de categorias para conhecer, pensar e classificar aquilo que é diferente. Sendo inerente à condição humana, a determinação de que todos, mulheres e homens, devem comer, dormir, trabalhar, reproduzir-se, rezar, não está dada ou não deveria estar dada segundo a forma pela qual cada grupo deve fazer cada uma dessas coisas.

Nesse contexto de relações as quais são inerentes à condição de pessoas e que deveriam ser respeitadas, levando-se em consideração as diferenças e não as imposições é que utilizaremos o método analítico da desconstrução. Método este que norteia as discussões provocadas pela teoria Queer e que são encantos, provocações, formas de se rever as relações que se estabelecem entre as categorias Gênero, Sexualidade, Identidade e Corpo.

O método empregado é o da desconstrução. Trata-se de método analítico em que o conceito de suplementaridade, utilizado por Jacques Derrida (2001), pontua que os significados são organizados por meio de diferenças em uma dinâmica de presença e ausência, ou seja, o que parece estar fora de um sistema já está dentro e o que parece natural é histórico. Com isso, Derrida (2001) propõe o método da Desconstrução, isto é, o procedimento analítico que mostra o implícito dentro de uma oposição binária - desconstrução é mostrar, é explicitar o jogo entre presença e ausência submetendo a estruturas e funcionamentos diferentes.

A teoria Queer assumirá para si esse método analíico, em que desfazer é identificar as formas pelas quais os sujeitos são interpelados por um gênero socialmente determinado em seu nascimento e de como sua trajetória de vida o leva à dissidência de gênero.

Ao identificarmos, nos discursos de $M$., práticas que levam a uma identidade elaborada pela normativa heterossexual, observamos a imposição de uma identidade de gênero. Esta, por sua vez, ao mesmo tempo em que é aceita em resposta a uma autoproteção, entra em conflito com o sentir-se, fazendo de sua percepção de gênero algo que esteja presente em um corpo que causa estranhamento. Esse sentir-se leva a um processo de desconstrução da identidade interpelada em seu nascimento. Assim, na constante movimentação de ausência e presença, o jogo da performatividade se dá ora na ausência de manifestação de sua identidade 
de gênero, ser, ver e se sentir mulher, ora na presença de autoproteção na sua incorporação de identidades com atributos masculinos e, portanto, composto na lógica heteronormativa. Esse referencial é tomado para compreendermos como as expressões perturbadoras da ordem social se manifestam enquanto desejo fora da norma heterossexual.

Assim, a masculinidade hegemônica se encontra nas estratégias da heteronormatividade, não apenas por essa pressupor que a heterossexualidade é o desejo pelo sexo oposto, mas por pressupor que a heterossexualidade é o padrão em qualquer tipo de relacionamento, sejam esses com pessoas do sexo oposto, bem como com pessoas do mesmo sexo (MISKOLCl, 2014).

Segundo Miskolci (2014), para a Teoria Queer,

tudo o que foge à norma é reconhecido como abjeto, recusado e - frequentemente - forcluído como fora dos limites do (re)conhecível, quer como objeto de conhecimento quer como digno de respeitabilidade moral e jurídica" (p. 9).

Uma proposta de análise desconstrutivista de discursos "não chega nunca a um significado final ou completo, pois o significado nunca está presente em si: ele é em vez disso, um processo que ocorre continuamente" (SALIH, 2013, p. 34).

O método desconstrutivista propõe às ciências sociais o intuito de desnaturalizar o social. Para isso, usa como mapa formas variadas de construtivismo social e histórico; o pensamento queer aposta na desconstrução como forma de compreensão deste mesmo meio que é o social.

A superação da categoria gênero, como posta até hoje, nos leva a pensar sobre as condições que possibilitam a emergência do movimento queer a ultrapassar as questões pontuais da política e da teorização gay e lésbica e que precisam ser compreendidas dentro do quadro mais amplo do pós-estruturalismo. A teoria queer pode ser vinculada às vertentes do pensamento que problematizaram as noções clássicas de sujeito, de identidade, de agência, de identificação (LOURO, 2001).

A teoria queer, por meio do método desconstrutivista, objetiva sua análise utilizando-se da análise do discurso como fonte de produção de saberes. Segundo Miskolci (2009), "ao invés de priorizar investigações sobre a construção social de identidades, estudos empíricos sobre comportamentos sexuais que levem a classificá-los ou compreendê-los" (p. 20), queer partirá de uma

desconfiança com relação aos sujeitos sexuais como estáveis e foca nos processos sociais classificatórios, hierarquizadores, em suma, nas estratégias sociais normalizadoras dos comportamentos" (MISKOLCl, 2009, p. 20). 
${ }^{9} M$. mulher trans, colaboradora da pesquisa, que em um corpo masculino, estranho a ela, busca afirmar uma condição de masculinidade hegemônica enquanto estratégia de poder e de autoproteção em seu ambiente de trabalho.

${ }^{10}$ Notamos que, para ela, se declarar uma mulher trans é uma forma de reconhecimento social, mas, ainda, distante de uma percepção de reconhecimento legal.
Queer mantém sua resistência aos regimes de normalidade, mas reconhece a necessidade de uma epistemologia do abjeto, baseada em investigações interseccionais. Essa epistemologia demonstra que o abjeto solicita e pulveriza, ao mesmo tempo, o sujeito. Assim, o induzirá a se reconhecer fora de si e se deparar com o impossível, verificando que o impossível é seu ser. Desta forma, o abjeto seria o ponto mais alto da experiência do sujeito (Julia KRISTEVA, 1982). Sendo assim, não são os sujeitos que têm experiências, mas, ao contrário, são as experiências que constituem os sujeitos (SCOT, 1990).

Existe uma diferença imensa entre o pertencimento a um grupo privilegiado. Portanto, dentro da heteronormatividade, o sujeito passa como se fosse uma pessoa que pertence a esse grupo privilegiado. É neste contexto que encontramos $M .{ }^{9}$ travesti que se intitula mulher trans, que, dentro de um corpo masculino, subverte sua existência por meio de estratégias masculinas de manutenção de poder. Assim, faz sentido a abjeção de si para o autorreconhecimento de si, de todo o seu ser, em termos de linguagem, significado e desejo (KRISTEVA, 1982).

Seguimos avançando na reflexão, na tentativa de compreender a significação que ela/ele - colaboradora da pesquisa - se dá quando se vê como uma pessoa trans (em suas palavras: "sou uma mulher" trans ${ }^{10}$ ), no sentido de se transformar, expressando sua variedade de experiências sobre como se identifica e mostrando que é possível ser mulher com pênis e, dessa maneira, ser percebida por outras pessoas sem colocar em evidência a sua dissidência de sexo assinada no nascimento. Neste caso, o fato significa que pessoas estão a identificando com aquilo que ela não é - acionando a violência chamada disforia -, ou ela/ele está se camuflando em algo em que não se reconhece, evitando sofrer certas violências. Em todos os casos pode surgir uma relação de hostilidade e violência a qualquer momento em que a pessoa for confrontada com sua transgeneridade.

\section{O estranhamento do corpo: desconstruindo a afirmação identitária}

A colaboração para o desenvolvimento dessa pesquisa, como já dito, foi dada por uma pessoa que se vê e se sente como mulher, mas que habita um corpo masculino, o qual é tomado pela estranheza. Quando, na performance e travestilidade masculina ela se reconhece como M.A.; quando, na percepção de sua feminilidade, ela se reconhece como $M$. As palavras, na narrativa discursiva de sua história de vida, são marcadas pela contradição, que, para nós, se define como uma inversão no processo de elaboração de suas identidades.

Estudos Feministas, Florianópolis, 25(2): 473-494, maio-agosto/2017 485 
A travestilidade, como veremos, se dá na ordem do feminino para o masculino. Portanto, o gênero está relacionado à performance, à prática e ao reconhecimento social. Mesmo incorporada do sexo compulsório masculino ligado ao seu nascimento, o estranhamento do próprio corpo a levará para uma condição de inversão de sua travestilidade.

Algumas considerações, ainda, se fazem necessárias para compreendermos a colaboradora dessa pesquisa. Sua identidade sexual, que abarca sentidos ambivalentes e contrastantes, atribui à sua personalidade um lugar supostamente duradouro que a orienta em seus desejos e sentimentos. Assim, o sentido de pertencimento a colocará como sujeito com um lugar, lugar este que se contradiz nas manifestações de seus desejos e sentimentos.

O lugar social em que ela se posiciona é significativamente relevante para a análise e, diante disto, também, o modo como nos referimos à sua pessoa, ou seja, enquanto profissão, trabalho, estilo de vida, posição social, expressões culturais e práticas eróticas associadas à forma de gestão de sexualidade e de identidades. Além disso, a idade (não revelada, mas marcada por expressões faciais de uma pessoa com experiência de vida), expressões corporais, a cor de cabelos, o modo de se vestir; mesmo podendo ter conotação de juízo de valores, constituídos historicamente, não podemos deixar de notar que a aparência física de $M$. é a de uma pessoa que teve uma vida sofrida e suas palavras não escondem esse sentimento. No entanto, ela procura, na busca de legitimação, se demonstrar uma pessoa com coragem e com vários momentos de alegria e superação.

Sua história de vida é marcada pela intersecção entre identidade de gênero e classe social. Nascida em família de condições econômicas precárias e sendo a mais velha da família, teve que cuidar de seus irmãos, após a perda da mãe. Esta é uma pista para pensar a respeito da constituição da subjetividade de ser $M$., já que, ao assumir o cuidado com os irmãos, de certo modo, assume o papel que, na sociedade é geralmente atribuído à mulher - marcando a matriz heteronormativa.

O sexo de nascimento é o masculino, mas, como veremos, sua percepção, enquanto existência e aceitação, é de identidade de gênero feminino. Isso é demonstrado de maneira um pouco confusa e contraditória em sua fala, pois há momentos em que se define como travesti, n'outros como uma transexual e n'outros como homem; são nessas marcas de indefinições que aprofundamos as análises, em que a não aceitação de um corpo e de uma identidade compulsória a coloca, muitas vezes, em contradição na relação com suas identidades. 
A colaboradora se apresenta de forma peculiar nos contatos que se deram em seu local de trabalho, uma escola de Ensino Fundamental localizada na periferia da Cidade de Barra do Garças - MT. Sua postura é determinada por uma identidade fixada em seu sexo de nascimento. Deste modo, ela constrói uma identidade que tem como referencial os comportamentos atribuídos sócio/histórica/ideologicamente ao gênero masculino.

Por ser seu local de trabalho, impor-se para a conquista de respeito é condição fundamental para que os preconceitos não se sobreponham nas relações interpessoais. Assim, assumir a identidade masculina é dar sentido à compreensão de existência enquanto forma de sobrevivência nesse ambiente. Por um lado, o seu travestimento em um homem comum, visualmente composto pelas formas da heterossexualidade compulsória, não foge às normas que seu sexo carrega. Por outro lado, sua homossexualidade está no vestir, no desejar e no sentir-se como mulher por meio da afirmação de sua sexualidade, pois, ao transitar nas duas esferas, heterossexualidade e homossexualidade, ela poderá, de maneira habitual, fazer uso de roupas e adereços femininos em qualquer esfera em que esteja.

É o caso de M.A. Sua apresentação, na forma de se vestir, pode ser classificada como comum - calças largas e despojadas, camiseta com logotipo do local de trabalho, um jaleco com o nome de registro bordado no bolso superior esquerdo, o que faz com que não deixe transparecer os pequenos seios que se escondem sob a vestimenta; o cabelo um pouco longo é preso por grampos.

As formalidades, nos cumprimentos, fazem referência à sua construção identitária masculina, mas logo é quebrada ao se dirigir: - "aqui tem que ser assim, se não o respeito por parte deles [grifos nossos] não acontece...". Essas palavras referem-se à forma de tratamento que tem com as/os alunas/ os da escola em que trabalha, isto é, impor-se como homem.

Posicionar-se como homem ou expressar-se a partir do gênero masculino é um ato de vivência de gênero funcional, representado no seu travestir-se [grifos nossos]; é o ato de desconstrução de sua percepção enquanto mulher e enquanto estratégia de sobrevivência. Nesse momento, $M$. se traveste em homem para se proteger em seu espaço de trabaIho. Estar como homem, constituído de atributos masculinos, a eleva a uma condição de ser respeitada por seus pares e demais membros da vivência escolar. Além do mais, não há a perda do controle na relação que ela estabelece com as crianças, pois é a forma que tem como referência enquanto estratégia de sobrevivência. A performance se dá com a repetição de atos presentes na constituição de uma identidade 
de gênero instituída naquele local. Fora dali ela pode ser o que desejar ser.

Em um dos encontros com M.A., ao perguntarmos o que, para ela, era ser travesti, o que seria uma travesti e quais seriam os atributos de uma travesti, obtivemos a seguinte resposta:

Primeiro lugar, eu acho que travesti é aquela pessoa que se traveste de um sexo, um jeito, uma personalidade a qual ela gostaria de ter e não tem. Vamos supor, por exemplo, a travesti feminina é aquela que veio como homem, mas se acha no corpo errado. Assim com o tempo mulher também, travesti homossexual feminina. Que acha que veio no corpo errado, vai se travestir de homem, vai cortar o cabelo de homem, fazer gesto, ato, meio, tudo como se fosse homem. Ou seja, ela acha que está no corpo errado, assim como também uma parte da travesti masculina. Ele acha que veio no corpo de um homem, acha que está no corpo errado, se sente errado, não se aceita daquele jeito, então ele vai se travestir da maneira que ele gosta. Vai se travestir o quê? Como mulher, né [grifos nossos].

Os destaques demonstram que seu discurso converge para a percepção de que o se sentir não está de acordo com o corpo:

[...] mas se acha no corpo errado. [...] Que acha que veio no corpo errado, [...] Ele acha que veio no corpo de um homem, acha que está no corpo errado, se sente errado, não se aceita daquele jeito, então ele vai se travestir da maneira que ele gosta [grifos nossos].

Seu sexo biológico se distancia de sua percepção de identidade de gênero, o que leva a uma constante desconstrução de sua condição, ora mulher - como se percebe e se sente -, ora homem - como se refugia na manutenção da sobrevivência, na construção de um modo de ser, de resistir.

É importante salientar que a repetição corpo errado traz, na materialidade da formulação, a possibilidade do gesto de interpretar que há uma forma de corpo que é certa; há um "corpo certo". Essa discursividade funciona sob a interpelação ideológica da normatividade. Estar no "corpo errado" é infringir uma regra, uma norma, é quebrar com o estabelecimento e, inscreve, no corpo mesmo, um efeito de sentido de crime. O travestimento é, de certo modo, sob a nossa reflexão, um aparato, também, de encobrimento, de disfarce.

A performatividade de uma travesti em sua elaboração de identidade não conforta a existência de M.A., pois garante que não tem mais a necessidade de ser performativa. O que importa é que o ser não está na forma pela qual se apresenta, 
mas pela forma como se sente - "está na mente, e a mente faz o corpo".

Não há mais necessidade de ser performativa enquanto se apresenta como $M$., visto que ser $M$., de fato, não é mais criar uma performance travesti, mas, sim, corresponder à sua real identidade de gênero. Identidade que está em consonância com sua sexualidade e, naturalmente, com seus desejos, com suas erotizações, seus amores.

Ao perguntarmos como ela se vê, como trans ou travesti, sua resposta é:

Eu me vejo sim. Como uma trans. Como uma, olha só. A travesti ela se vê tanto, até em determinado momento eu posso me considerar até como uma travesti, mas eu acho que a travesti se vê tanto incomodada com essa personalidade de gênero que ela quer mostrar pra sociedade que ela é mulher. Por isso, ela vive vinte quatro horas, vinte e quatro horas, vestida como mulher. Porque ela acha que a sociedade não está vendo ela. $E$ é verdade. Verdade, a sociedade fecha os olhos [grifos nossos].

Observemos que, para M.A., há uma invisibilidade das travestis na sociedade e que, portanto, o travestir-se é mais que o sentir-se mulher; é se mostrar para tornar-se visível, é se posicionar como mulher na sociedade. Essa invisibilidade só ganha notoriedade, ou seja, transpassa a ordem social vigente, quando as travestis passam a incomodar a sociedade. No caso das travestis na cidade de Barra do Garças, a sociedade delega a elas uma territorialização que as apaga. O espaço urbano, simbolicamente constituído e destinado para o trabalho das travestis, é as margens da rodovia que corta a cidade. Ironicamente, a cidade cresceu e incorporou com construções comerciais essa margem rodoviária, porém, ainda está situada em locais escuros em que as travestis se protegem da violência se esquivando atrás de sombras dos postes de iluminação.

A visibilidade só se tornará possível quando, utilizandose de estratégias das quais $M$. se apodera, a travestilidade se inverta em suas montagens. A presença nem sempre é o que dá significado à existência, pois, neste caso, é na ausência que encontramos manifesta a identidade. Isso fica mais claro quando ela continua sua exposição:

Já a pessoa que se sente como trans, o jeito que a gente vê, a pessoa não vê. Não importa se ele está vestido do modo de trabalho, como eu estou vestido aqui pra trabalhar, trabalhar em serviço formal, não um serviço que envolve prostituição, um serviço formal, concurso e tudo, mas ela se acha uma mulher. Por que ser mulher, elas entendem, algumas das travestis 
também entendem, ser mulher não está na roupa, não está em você sair vestido pela sociedade, vestido na rua, gritando "eu sou mulher". Está na mente, e a mente faz o corpo. Estou me sentindo aqui uma mulher, fazendo uma avaliação, fazendo uma participação em um projeto de graduação. Projeto que eu já passei por isso, não pretendo parar, vou dar continuidade. Estou continuando, pretendo fazer especialização. Sou especialista. E vou continuar. Mas eu vou continuar desse meu jeito aqui. Eu me sinto uma mulher [grifos nossos].

Na distinção que ela faz entre travesti e trans, sua percepção de mulher ultrapassa o vestir-se, indo da mente numa transferência para o corpo. A percepção do gênero não está mais na genitália, mas no se sentir que se transfigura na imposição de ser feminino. A desconstrução e, portanto, a negação de gênero imposto em seu nascimento leva ao estranhamento do corpo e a contradições perceptíveis.

Ao se apresentar publicamente, como se apresentou em nossos encontros, M.A. se mostra confiante em sua afirmação identitária de trans. Na definição de trans como 'transformada', ela se vê como sendo um processo pelo qual foi se transformando em suas transições de fases vividas. A percepção de sua transformação associa-se à sexualidade, na descoberta que faz da percepção de um sentimento que não condiz com o corpo ao qual se encontra. Ser trans é visto como uma transformação de sua condição, agora não mais de $M . A$., mas em $M$. como algo real.

O que M.A. não percebe é que, para ela, estar como M.A. é performatizar a sua condição masculina num jogo criado como estratégia de sobrevivência, de resistência. Sua identidade real é ser mulher. Assim, a desconstrução, na relação presença e ausência, aparece na condição de estar homem, com todos os elementos de elaboração da masculinidade hegemônica, e em ser mulher; não numa condição de aparência, mas, sim, na condição existência.

Ser mulher está na alma, num corpo instituído pela alma. Vejamos:

Eu já sou meu bem. Eu me apresento. Não tem como. Não adianta uma pessoa passar aqui, por exemplo, e falar que é dois homens conversando. Vão falar "é um homem e uma travesti. Ou um homem e um gay, como atualmente eles dizem né. Não vai falar ainda um homem e uma trans porque essa terminação trans é recente. De pouco tempo pra cá. Trans quer dizer transformada. Todos nós somos transformados. Imagina um homem. Um homem é considerado trans. Você é um trans. Porque você se transformou em homem, de criança, menino, pra homem. Né. Ela, a fulana, se transformou de menina pra homem. É complicado. Em 
termos de trans pra em termos de sexualidade, é aquela travesti que está se descobrindo, que está se vendo como uma mulher. Porque mulher e homem não está na roupa, no jeito de vestir, não está no jeito de andar, não está com quem você fala, com quem você conversa, aonde você anda, como você faz, mas sim, está na mente e no corpo. Ser mulher é corpo e alma [grifos nossos].

\section{"Ser mulher é corpo e alma": algumas considerações}

Relatos de experiências vividas são fonte privilegiada de saberes sobre as relações que se estabelecem socialmente, no caso específico, por meio de um processo de desconstrução de identidades socialmente projetadas. Refletir sobre as razões que levam $M$. a buscar, em sua história de vida, portanto, um arquivo vivo, muitas vezes mais rico e multifacetado do que o existente nas fontes oficiais, nos leva a compreender todo o seu processo de desconstrução de suas identidades. Explorar as diferentes maneiras de como a Sociologia e outras ciências se voltaram para a análise em busca de visões que levem a um aprofundamento teórico das diversas histórias, testemunhos e informações de quem viveu, sofreu e, muitas vezes, até pereceu sem que suas vidas tivessem sido reconhecidas, contribui para esse processo.

M. é mulher de corpo e alma [grifos nossos]. Sua construção identitária reflete em todas as suas expressões, se contradiz em sua necessidade de sobrevivência em uma sociedade marcada pela heteronormatividade, que faz dela uma pessoa em constante transitar.

O travestir-se é o refúgio de sua sobrevivência, mas não um travestir-se como usualmente visto e pensado, isto é, na transformação de homem em mulher utilizando-se de diversos aparatos femininos, como: roupas, sapatos, maquiagem e adereços. Seu refúgio é o travestir-se na sua desconstrução, é sair da sua condição feminina e transformarse em homem. M. passa a ser M.A., passa a se "proteger" em seu gênero compulsório, travestindo-se em homem, para sobreviver na dignidade de seu sentir-se mulher. A inversão é marcada pela necessidade de sua autoproteção; o protegerse de uma sociedade marcada pelo preconceito, pautada na heteronormatividade.

Ao desconstruir sua identidade de gênero masculina, M. marca em seu corpo sua sexualidade homoerótica, fazendo dela um sujeito que luta pelo expressar-se em seus desejos e expressões corporais. Ao afirmar a sua diferença, M. está afetando, por exemplo, uma colocação flamejante, na marcação da recusa aos estereótipos, privilegiando uma 
apresentação de si feminina, ou, mesmo, no processo de produzir a confusão, misturando os signos, no jogo sobre as aparências e performance que está no cerne das identidades assumidas por ela, pois permite expressar, ao mesmo tempo, uma sensibilidade pessoal.

Para dar efeito de fechamento ao texto, reiteramos: o que importa é que o ser não está na forma pela qual se apresenta, mas pela forma que se sente - "está na mente, e a mente faz o corpo".

A pesquisa que originou este artigo foi apoiada pelo CNPq (Edital Universal 2014) e FAPEMAT (Edital Universal 2014).

\section{Referências}

ALVAREZ, Sônia. Manual relações de Gênero no ciclo de projetos. São Paulo: Rede Mulher, 1997.

BUTLER, Judith. Problemas de Gênero: feminismo e subversão da identidade. Tradução de Renato Aguiar. Rio de Janeiro: Civilização Brasileira, 2003.

CONNELL, Robert W.; MESSERSCHMIDT, James W. "Masculinidade hegemônica: repensan-do o conceito". Revista Estudos Feministas, Florianópolis, v. 21, n. 1, p. 424, janeiro-abril 2013.

COURTINE, Jean-Jacques. "Apresentação". In: CORBIN, Alain; COURTINE, Jean-Jacques; VIGARELLO, Georges. História do corpo: as mutações do olhar. O século XX. 4.ed. Petrópolis: Vozes, 2011.

DERRIDA, Jacques. Gramatologia. Tradução de Renato Janine Ribeiro. São Paulo: Perspectiva, 2011.

FOUCAULT, Michel. A ordem do discurso. 9.ed. São Paulo: Loyola, 2003.

JESUS, Jaqueline Gomes de. Orientação sobre a população transgêneros: conceitos e termos. Brasília: Autor, 2012.

INSTRAW. Conceitos de Gênero no Planejamento do Desenvolvimento. Uma abordagem básica. Brasília: Conselho dos Direitos da Mulher do Distrito Federal - GDF, 1995

KRISTEVA, Julia. Powers of Horror: an Essay on Abjetion. Nova York: Columbia University Press, 1982.

LOURO, Guacira L. Gênero, sexualidade e educação: uma perspectiva pós-estruturalista. 5.ed. Petrópolis: Vozes, 2003.

(Org.). O corpo educado: pedagogia da sexualidade. Belo Horizonte: Autêntica, 2001a.

"Teoria Queer - uma política pós-identitária para a educação". Revista Estudos Feministas, ano 9, $2^{\circ}$ semestre 2001.

MISKOLCI, Richard. "A teoria queer e a sociologia: o desafio de uma analítica da normalização". Sociologias, Porto Alegre, ano 11, n. 21, p. 150-182, jan./jun. 2009. 
. Marcas da diferença no ensino escolar. São Carlos: EDUfscar, 2014.

Teoria queer: um aprendizado pelas diferenças. 2.ed. Belo Horizonte: Autêntica/UFOP - Universidade Federal de Ouro Preto, 2013.

SALIH, Sara. Judith Butler e a teoria queer. Belo Horizonte: Autêntica, 2013.

SCOTT, Joan W. "Gênero: uma categoria útil de análise histórica”. Revista Educação e Realidade, v. 16, n. 2, p. 5-22, jul./dez. 1990.

ZAMBRANO, Elizabeth; HEILBORN, Maria Luiza. "Identidades de Gênero". In: LIMA, Antonio Carlos de Souza (Coord.). Antropologia e Direito: temas antropológicos para estudos jurídicos. Brasília; Rio de Janeiro; Blumenau: Associação Brasileira de Antropologia/LACED/Nova Letra, 2013.

ZOLIN, Lúcia Osana. "Crítica feminista". In: BONNICl, Thomas; ZOLIN, Lúcia Osana (Orgs.). Teoria Literária: abordagens históricas e tendências contemporâneas. 2.ed. Maringá: EDUEM, 2005.

ZOPPI-FONTANA, Mónica Graciela. "Mulheres em discurso: processos de subjetivação e práticas de resistência". Simpósio temático 87. FAZENDO GÊNERO 10, Florianópolis, Universidade Federal de Santa Catarina, 2013. Disponível em: http://www.fazendogenero.ufsc.br/10/simposio/ view?ID_SIMPOSIO=293/2014.

[Recebido em 25/11/2015,

reapresentado em 10/08/2016

e aprovado em 29/08/2015]

Travesty the Reverse - the Deconstruction of Identity Parody

Abstract: In this article, we discuss about the so-called gender identities, given the complexity and the emergence of the issue, especially in recent times. The purpose is to explore discursive ambiguity in Case in which it identifies a transvestite, resident in the city of Barra do Garças/ MT that in the perception of speech itself, let estrangement brands of the body. In our opinion, such marks lead to a deconstruction of their identities, in a performative movement and contradictory in which dresses as a man, even lying in a male body, did not recognize. By making use of his sexual organ of birth, is in the development of coping strategies. The basis of the analyzes are theories of gender and queer, deconstruction proposals of sexuality meanings.

Key words: Deconstruction; Gender; Sexuality; Trasvesty; Identity.

Luís Antonio Bitante Fernandes (bitante67@hotmail.com) é professor adjunto da Universidade Federal de Mato Grosso, lotado no Instituto de Ciências Sociais e Humanas do Campus Universitário do Araguaia. É mestre em Sociologia pela PUC-SP e doutor pela UNESP/Araraquara. Suas áreas de atuação são Sociologia e Antropologia, especificamente nos estudos sobre relações de gênero, sexualidade, identidade, masculinidade e travestilidade. 
Águeda Aparecida da Cruz Borges (guidabcruz@hotmail.com) é graduada em Letras pela Universidade do Estado de Mato Grosso, mestre em Lingüística pela Universidade Estadual de Campinas-UNICAMP, doutora em Linguística pela Universidade Estadual de Campinas e é professora Adjunto I da Universidade Federal de Mato Grosso. Atua na área de Linguística, tem experiência na área de Educação, com ênfase em Métodos e Técnicas de Ensino, Experiência em Formação de professores alfabetizadores e ensino de Língua Portuguesa (2a língua) para povos indígenas.

Rodolfo Pinheiro Bernardo Lôbo (therodolfolobo@gmail.com) é graduado em Direito pela Universidade Federal de Mato Grosso/ Campus Universitário do Araguaia. Tem experiência na área de Direito atuando principalmente nos seguintes temas: Direito Constitucional, Direitos Humanos, Direito de Família e Sucessões e Direitos Difusos e Coletivos. 